\title{
Desempenho de juvenis de tilápia-do-nilo alimentados com rações contendo complexo enzimático
}

\section{Arcangelo Augusto Signor ${ }^{1}$, Wilson Rogério Boscolo², Fábio Bittencourt ${ }^{3}$, Aldi Feiden², Giovani Sampaio Gonçalves ${ }^{4}$, Jakeline Marcela Azambuja de Freitas ${ }^{5}$}

\author{
${ }^{1}$ Doutorando em Zootecnia, UEM. Rua da Faculdade, 645, CEP: 85900-000, Toledo, Paraná. \\ 2 Programa de Pós-Graduação em Zootecnia e em Recursos Pesqueiros e Engenharia de Pesca-Universidade Estadual do Oeste do Paraná. \\ ${ }^{3}$ Doutorando em Aquicultura, CAUNESP/UNESP. \\ 4 Instituto de Pesca de São José do Rio Preto - São Paulo. \\ ${ }^{5}$ Mestrando em Zootecnia - Universidade Estadual do Oeste do Paraná.
}

RESUMO - Avaliou-se o efeito da inclusão de um complexo enzimático em dietas para tilápias-do-nilo (Oreochromis niloticus) sobre o desempenho, a composição química da carcaça e a qualidade da água. Foram utilizados 200 alevinos revertidos $(4,57 \pm 1,24 \mathrm{~g})$, distribuídos em delineamento inteiramente casualizado em 20 tanques de 500 litros, com quatro tratamentos e cinco repetições, considerando a unidade experimental uma caixa com dez peixes. Os peixes foram alimentados com dietas contendo 0; 0,033; 0,066 ou 0,099\% de complexo enzimático. As dietas foram processadas na forma peletizada e fornecidas quatro vezes ao dia, às $8,11,14$ e 17 h. Os valores médios de $\mathrm{pH}$, condutividade elétrica, oxigênio dissolvido, temperatura, fósforo total, amônia e nitrato da água de cultivo não foram influenciados pela dieta. A inclusão do complexo enzimático na dieta não afetou o ganho de peso, as taxas de sobrevivência e de crescimento específico, mas influenciou o consumo de ração e a conversão alimentar, cujos valores foram maiores nos peixes alimentados com a dieta com 0,066\% de complexo enzimático. Não foram observadas diferenças nos teores de matéria seca, umidade, proteína bruta, matéria mineral, cálcio e fósforo na carcaça dos peixes, no entanto, o teor de extrato etéreo reduziu de forma linear com o aumento do nível de complexo enzimático. A utilização de complexo enzimático (amilase, protease, celulase, lipase, pectinase, xilanase, $\beta$-glucanase e fitase) no nível de $0,066 \%$ em dietas para juvenis de tilápia-do-nilo piora a conversão alimentar, mas não influencia o desempenho e a composição corporal dos peixes.

Palavras-chave: enzimas, nutrição, peixes, qualidade de água

\section{Performance of juvenile Nile tilapia fed diets with enzymatic complex}

ABSTRACT - The aim of this study was to evaluate the inclusion of an enzimatic complex in diets for Nile tilapia (Oreochromis niloticus) on performance, carcass chemical composition as well as water quality. The experiment was performed in 62 days. It was used two hundred reverted fingerlings (14.57 $\pm 1.24 \mathrm{~g})$ distributed in a complete randomized design in 20500 L-tanks with four treatments and five replicates, considering a box with 10 fish as a experimental unit. The fish were fed diets containing $0 ; 0.033 ; 0.066$ and $0.099 \%$ of enzimatic complex. The diets were processed in peletized way and supplied four times a day (8:00 a.m., 11:00 a.m., 2:00 p.m. and 5:00 p.m.) The pH average values, electric conductivity, dissolved oxygen, temperature, total phosphorus, ammonia and water nitrate of the cultivation were not influenced by the inclusion of the enzimatic complexin the diet. The inclusion of enzymatic complex in the diet did not affect weight gain, survival, and specific growing rate; however, it affected diet consumption and food conversion, whose values were greater for fish fed $0.066 \%$ of enzimatic complex diet. No differences were observed on dry matter, humidity, crude protein, mineral matter, calcium and phosphorus in the fish carcass, nevertheless, the ether extract decreased linearly as the level of enzymatic complex increased. The utilization of enzimatic complex (amylase, protease, cellulase, lipase, pectinase, xylanase, $\beta$-glucanase and phytase) at the level of $0.066 \%$ for juvenile Nile tilapia (Oreochromis niloticus) worsens food conversion but does not influence performance and body composition of the fish.

Key Words: enzymes, fish, nutrition, water quality

Recebido em 26/9/2008 e aprovado em 4/5/2009.

Correspondências devem ser enviadas para: angelo_signor@hotmail.com 


\section{Introdução}

O cultivo de tilápias em tanques-rede no Brasil cresce em um ritmo acelerado devido ao grande potencial hídrico, à temperatura adequada e à disponibilidade de alimentos para elaboração de rações balanceadas. Nos atuais sistemas de produção, emprega-se a tilápia-do-nilo pelo fato de possuir grande rusticidade e tolerar alta densidade de cultivo. Desta forma, a dieta deve atender as exigências dos peixes, pois o confinamento limita o acesso a outras fontes de alimentos (Sampaio \& Braga, 2005; Furuya et al., 2004a; Marengoni, 2006).

Em criações intensiva e semi-intensiva, a alimentação corresponde à maior parcela do custo total de produção. As enzimas exógenas permitem aumentar a digestibilidade dos nutrientes, melhorando o desempenho produtivo de peixes e reduzindo a excreção de nutrientes. Podem também reduzir os custos com alimentação, pelo baixo valor de aquisição e por serem incluídas em pequenas quantidades nas dietas.

As enzimas são proteínas que aumentam a velocidade das reações sem alterar o processo global (Champ et al., 2006). Algumas enzimas não são secretadas mesmo com a presença de substrato, como é o caso da celulase, hemicelulase, xilanase e da fitase. Atualmente, por meio de técnicas de recombinação genética e mutações, a biotecnologia tem possibilitado a produção industrial de enzimas exógenas específicas, utilizando diversos tipos de fungos, bactérias e plantas (Silva et al., 2007a).

O uso de enzimas digestivas exógenas em dietas com elevados valores de inclusão de alimentos de origem vegetal para peixes tem despertado grande interesse, pois auxilia na digestibilidade e reduzem a poluição ambiental (Gomes et al., 2000; Silva et al., 2000; Silva et al., 2007a). Os complexos enzimáticos atuam rompendo as paredes celulares (Torres et al., 2003), destruindo ou inibindo a ação de fatores antinutricionais e possibilitando a inclusão de matérias-primas de menor qualidade às dietas de animais domésticos (Nery et al., 2000) e peixes (Ng et al., 2002). Os fatores antinutricionais não são tóxicos aos peixes, mas sua presença pode resultar em redução no crescimento e aumento da conversão alimentar e provocar alterações hormonais (Francis et al., 2001).

Neste trabalho avaliou-se o efeito da inclusão de um complexo enzimático (Cenzyme ${ }^{\circledR}$ ) (amilase, protease, celulase, lipase, pectinase, xilanase, $\beta$-glucanase e fitase) no desempenho produtivo, na qualidade da água e na composição química da carcaça de juvenis de tilápia-donilo (Oreochromis niloticus).

\section{Material e Métodos}

O experimento foi desenvolvido no Laboratório de Aquicultura da Universidade Estadual do Oeste do Paraná, Campus de Toledo, e teve duração de 62 dias (2/4 a $31 / 5 / 2008)$. Foram utilizados 200 peixes com 14,57 \pm 1 ,24 g distribuídos em delineamento inteiramente casualizado, com quatro tratamentos e cinco repetições, considerando unidade experimental um tanque de $500 \mathrm{~L}$ com dez peixes, em sistema de recirculação de água.

Os animais foram alimentados com dietas contendo 0; 0,033; 0,066 ou 0,099\%) de complexo enzimático (Cenzyme ${ }^{\circledR}$ ) composto por amilase, protease, celulase, lipase, pectinase, xilanase, $\beta$-glucanase ou fitase. As dietas foram formuladas visando atender à exigência da espécie (NRC, 1993) e continha 30\% de proteína digestível e 3.100 kcal de energia digestível/kg. Os nutrientes digestíveis foram calculados segundo os valores observados por Boscolo et al. (2002), Meurer et al. (2003) e Boscolo et al. (2008) (Tabela 1).

Para o processamento das dietas, os alimentos foram pesados, pré-misturados e moídos em triturador tipo martelo com peneira de $0,8 \mathrm{~mm}$. Posteriormente, foi realizada uma nova mistura e incorporados o complexo enzimático e o suplemento mineral e vitamínico. Em seguida, a mistura foi

Tabela 1 - Composição da dieta de alevinos de tilápia-do-nilo

\begin{tabular}{lc}
\hline Item & $(\%)$ \\
\hline Farelo de soja & 44,792 \\
Milho & 33,171 \\
Farinha de tilápia & 13,918 \\
Farinha de vísceras de aves & 5,321 \\
Calcário calcitico & 1,071 \\
Fosfato bicálcico & 0,707 \\
Suplemento (mineral + vitamínico) ${ }^{1}$ & 0,500 \\
Sal & 0,500 \\
Antioxidante (BHT) & 0,020 \\
Nutriente & \\
Cálcio (\%) & 2,000 \\
Energia digestível (kcal/kg) ${ }^{2}$ & 3100 \\
Proteína digestível (\%) ${ }^{2}$ & 30,000 \\
Fibra bruta (\%) & 3,364 \\
Fósforo total (\%) & 1,000 \\
Gordura (\%) & 5,372 \\
Linoleico (\%) & 1,068 \\
Lisina (\%) & 2,029 \\
Metionina+cistina (\%) & 1,218 \\
Metionina (\%) & 0,626 \\
\hline
\end{tabular}

${ }^{1}$ Níveis de garantia por quilograma do produto: vit. A - $500.000 \mathrm{UI}$; vit. $\mathrm{D}_{3}$ 200.000 UI; vit. E - 5.000 mg; vit. K3 - 1.000 mg; vit. B1 - 1.500 mg; vit. B2 $1.500 \mathrm{mg}$; vit. B6 - $1.500 \mathrm{mg}$; vit. B12 - $4.000 \mathrm{mg}$; ácido fólico - $500 \mathrm{mg}$; pantotenato de cálcio - $4.000 \mathrm{mg}$; vit. C - $15.000 \mathrm{mg}$; biotina - $50 \mathrm{mg}$; inositol 10.000; nicotinamida - 7.000; colina - $40.000 \mathrm{mg}$; cobalto - $10 \mathrm{mg}$; cobre - $500 \mathrm{mg}$; ferro - $5.000 \mathrm{mg}$; iodo - $50 \mathrm{mg}$; manganês - $1.500 \mathrm{mg}$; selênio - $10 \mathrm{mg}$; zinco $5.000 \mathrm{mg}$.

${ }^{2}$ Valores de energia e proteína digestíveis propostos por Boscolo et al. (2002), Meurer et al. (2003) e Boscolo et al. (2008). 
submetida ao processo de peletização em equipamento tipo moedor de carne, marca Beccaro ${ }^{\circledR}$, equipado com matrizes de 3,0 mm. Para esse procedimento, a dieta farelada foi umedecida com água a $50^{\circ} \mathrm{C}$, peletizada e, posteriormente, seca em estufa de ventilação forçada por 12 horas a $55^{\circ} \mathrm{C}$, resultando em um produto com cerca de $10 \%$ de umidade.

Os peixes foram alimentados quatro vezes ao dia (8; 11; 14 e 17 h) até a saciedade aparente dos animais. Para o controle do consumo, as dietas foram pesadas, armazenadas em recipientes plásticos com tampa e permaneceram em geladeira durante o período experimental. No final do experimento, as sobras das dietas foram pesadas para determinação do consumo, da conversão alimentar e da eficiência alimentar.

Ao final do experimento, os peixes permaneceram por 12 horas sem alimentação para esvaziamento do trato digestório. Posteriormente, foram insensibilizados em gelo, pesados, medidos, eviscerados, embalados e congelados para análise de composição bromatológica da carcaça segundo metodologia descrita pela AOAC (2000).

Foram avaliados o ganho de peso, o consumo de ração, a conversão alimentar, a taxa de eficiência alimentar, a sobrevivência e a taxa de crescimento específico. Os parâmetros físico-químicos da água, como $\mathrm{pH}$, condutividade elétrica e oxigênio dissolvido foram monitorados semanalmente, enquanto a temperatura foi monitorada diariamente às 8 e $17 \mathrm{~h}$. No último dia do experimento, foram analisados o fósforo total, amônia e o nitrato da água dos tanques utilizando-se kits da empresa AlfaKit ${ }^{\circledR}$.

Os dados obtidos foram submetidos à análise de variância a 5\% de significância e avaliados por regressão polinomial e pelo teste de Duncan pelo programa estatístico SAEG(UFV,1997).

\section{Resultados e Discussão}

A inclusão de 0,0; 0,033; 0,066 e 0,099\% de complexo enzimático na dieta não influenciou $(\mathrm{P}>0,05)$ os parâmetros de qualidade água (Tabela 2). Os valores médios de temperatura, oxigênio dissolvido, $\mathrm{pH}$ e condutividade elétrica da água monitorada durante o período estudado permaneceram dentro da faixa do conforto térmico recomendada para a produção de peixes de clima tropical (Boyd, 1990; Sipaúba-Tavares, 1995).

Os compostos fosfatados e nitrogenados oriundos da alimentação influenciam negativamente a qualidade da água, pois são os principais nutrientes eutrofizadores dos ambientes aquáticos. Bock et al. (2007) avaliaram a disponibilidade de fósforo proveniente dos vegetais comparando três níveis de fitase (1.000, 1.500 e 2.00 unidades de fitase) e uma ração com suplementação de fósforo (4\% de fosfato bicálcico) e relataram que o mineral presente nas fezes reduziu com a inclusão dessa enzima. OliviaTeles et al. (1998) observaram que a inclusão de 1.000 e 2.000 unidades de fitase em dietas para alevinos de sea bass Dicentrarchus labrax reduziu significativamente a excreção de fósforo fecal. No entanto, conforme observado neste experimento, a inclusão do complexo enzimático (Cenzime ${ }^{\circledR}$ ) não influenciou a concentração de fósforo e ortofosfato (Tabela 2) na água de cultivo de juvenis de tilápia-do-nilo. Aparentemente, os níveis de fósforo disponível intrínseco dos ingredientes, somados à suplementação de fosfato bicálcico, garantiram a exigência desse mineral no desempenho produtivo dos exemplares juvenis de tilápia, impedindo a atuação das enzimas em maior ou menor intensidade.

Os valores médios de ganho de peso e taxa de crescimento específico não diferiram $(\mathrm{P}>0,05)$ entre os níveis de inclusão do complexo enzimático (Tabela 3). Entretanto, os resultados de consumo de ração, conversão alimentar e taxa de eficiência alimentar diferiram significativamente $(\mathrm{P}<0,05)$ entre os níveis de inclusão. Os mais baixos consumos de ração foram observados nos peixes alimentados com dietas contendo 0,066 e 0,099\%, diferindo $(\mathrm{P}<0,05)$ daqueles que receberam dietas com 0,033\% do complexo enzimático e controle. Os valores

Tabela 2 - Parâmetros de qualidade da água dos tanques de cultivo de juvenis de tilápia-do-nilo

\begin{tabular}{|c|c|c|c|c|c|}
\hline \multirow[t]{2}{*}{ Item } & \multicolumn{4}{|c|}{ Complexo enzimático (\%) } & \multirow[t]{2}{*}{ CV (\%) } \\
\hline & 0,000 & 0,033 & 0,066 & 0,099 & \\
\hline Temperatura manhã $\left({ }^{\circ} \mathrm{C}\right)$ & 24,40 & 24,41 & 24,34 & 24,43 & $1,072^{\mathrm{ns}}$ \\
\hline Temperatura tarde $\left({ }^{\circ} \mathrm{C}\right)$ & 24,39 & 24,53 & 24,54 & 24,40 & $1,839^{\mathrm{ns}}$ \\
\hline Oxigênio dissolvido (mg/L) & 3,79 & 3,78 & 3,79 & 3,77 & $26,313^{\text {ns }}$ \\
\hline Potencial hidrogeniônico & 7,84 & 7,82 & 7,52 & 7,81 & $8,916^{\mathrm{ns}}$ \\
\hline Condutividade elétrica (mg/L) & 105,71 & 105,64 & 105,58 & 105,75 & $1,652^{\mathrm{ns}}$ \\
\hline Fósforo total $\left(\mathrm{P}_{2} \mathrm{O}_{5}\right)(\mathrm{mg} / \mathrm{L})$ & 3,36 & 3,16 & 7,80 & 6,77 & $65,997^{\mathrm{ns}}$ \\
\hline Amônia $\left(\mathrm{NH}_{3}\right)(\mathrm{mg} / \mathrm{L})$ & 0,24 & 0,20 & 0,23 & 0,19 & $32,510^{\mathrm{ns}}$ \\
\hline Nitrato $\left(\mathrm{NO}_{3}\right)(\mathrm{mg} / \mathrm{L})$ & 3,71 & 3,42 & 3,25 & 4,01 & $19,767^{\text {ns }}$ \\
\hline
\end{tabular}

* $(\mathrm{P}<0,05)$. 
médios de conversão alimentar e a taxa de eficiência alimentar foram melhores índices nos peixes alimentados com dietas contendo 0,066 e 0,099\% de complexo enzimático. Não foi observada mortalidade de animais durante o experimento.

Os valores médios de consumo de ração, conversão alimentar e taxa de eficiência alimentar comprovam que a inclusão de $0,066 \%$ de complexo enzimático disponibilizou maior quantidade de nutrientes, levando os peixes a menor consumo de ração, apesar do ganho de peso similar. A enzima lipase disponibiliza energia de natureza não-proteica aos lipídios causando efeito poupador de proteína como fonte energética (Nunes et al., 2006). Os complexos enzimáticos formados por enzimas com características sinérgicas e aditivas são mais eficientes no aproveitamento da energia e proteína dos alimentos por agirem de forma complementar e simultânea (Oliveira et al., 2007).

Os resultados neste estudo corroboram aqueles obtidos por Bock et al. (2007), que avaliaram a eficiência da fitase em disponibilizar o fósforo dos alimentos. Esses autores avaliaram três níveis de enzimas (1.000, 1.500 e 2.000 UF) e uma dieta com suplementação de fósforo (4\% de fosfato bicálcico) para alevinos de tilápia-do-nilo. Nesse estudo, observaram que as médias de ganho de peso, conversão alimentar, taxa de eficiência proteica e taxa de eficiência de fósforo foram mais altas nos peixes alimentados com dietas suplementadas com fósforo em comparação àquelas suplementadas com fitase, comprovando que o teor de fósforo nas dietas sem a suplementação de fosfato bicálcico foi insuficiente, mesmo com a adição dessa enzima. Neste trabalho, a inclusão do complexo enzimático nos níveis de 0,066 e $0,099 \%$ melhorou significativamente $(P<0,05)$ a conversão alimentar dos animais.

A comparação dos resultados obtidos neste estudo com os preconizados na literatura é bastante complexa, visto que pesquisadores utilizam tanto enzimas isoladas como complexos enzimáticos. Entre as enzimas mais utilizadas na alimentação de peixes, deve se destacar a fitase (Vielma et al., 1998; Furuya et al., 2001; Furuya et al., 2004b;
Gonçalves et al., 2004; Sajjadi \& Carter, 2004; Bock et al., 2006; Furuya et al., 2006; Bock et al., 2007; Gonçalves et al., 2007; Silva et al., 2007b; Rocha et al., 2008). Recentemente, têm-se realizado estudos utilizando complexos enzimáticos como os descritos por Nunes et al. (2006), Oliveira et al. (2007), Silva et al. (2007a), Correa et al. (2007) e Moura et al. (2007), que relataram os efeitos da suplemen-tação de enzimas. Entretanto, não há relatos de malefícios da inclusão dessas enzimas na digestibilidade dos nutrientes nem no desempenho dos peixes.

Estudos com suínos e aves foram desenvolvidos por Bedford (2000), Garcia (2000), Tejedor et al. (2001), Cotta et al. (2002), Fischer (2002), Torres et al. (2003), Costa et al. (2004), Teixeira et al. (2005), Ruiz et al. (2008), Fukayama et al. (2008), Silva et al. (2008), porém, nestes trabalhos há relatos que a suplementação de enzimas nem sempre melhora o desempenho produtivo desses animais, como os descritos por Fischer et al. (2002) de que a inclusão de complexo enzimático (Vegpro) em dietas à base de milho e farelo de soja não melhorou o desempenho de frangos de corte. Também para suínos, Ruiz et al. (2008) relataram que a inclusão do complexo enzimático (amilase, celulase, pentosanase, $\alpha$-galactosidase e protease) em dietas com milho e farelo de soja, não melhorou a digestibilidade dos nutrientes nem o desempenho dos animais.

Nos peixes, também foram registradas diferenças na utilização de complexo enzimático, segundo relatos de Furuya et al. (2004b) de que os valores de peso final, comprimento final e sobrevivência não apresentaram diferenças quando incluíram 0, 500, 1.000, 2.000 e 4.000 UF nas dietas para larvas de tilápia-do-nilo. Esse fato pode estar relacionado à grande variação nos valores médios de desempenho. Entretanto, foi observado efeito linear na retenção de cálcio e efeito quadrático na retenção de fósforo na carcaça dos animais. Rocha et al. (2008), também avaliaram a inclusão de $0,500,1.000$ e 1.500 UF em dietas para juvenis de jundiá (Rhamdia quelen) e relataram que os níveis de 500 a 1500 UF na dieta não melhoram o desem-

Tabela 3 - Desempenho de juvenis de tilápia-do-nilo submetidas ao complexo enzimático

\begin{tabular}{lccccc}
\hline Item & \multicolumn{3}{c}{ Complexo enzimático (\%) } & CV (\%) \\
\cline { 2 - 5 } & 0,000 & 0,033 & 0,066 & 0,099 & \\
\hline Peso inicial (g) & 14,40 & 14,20 & 14,98 & 14,70 & $9,048 \mathrm{~ns}$ \\
Ganho de peso (g) & 48,22 & 45,32 & 46,51 & 42,43 & $5,416 \mathrm{~ns}$ \\
Consumo de ração (g) & $72,36 \mathrm{~b}$ & $83,55 \mathrm{a}$ & $58,97 \mathrm{c}$ & $60,29 \mathrm{c}$ & $8,787 *$ \\
Conversão alimentar & $1,50 \mathrm{~b}$ & $1,84 \mathrm{a}$ & $1,26 \mathrm{c}$ & $1,30 \mathrm{c}$ & $9,714^{*}$ \\
Taxa de eficiência alimentar & $0,67 \mathrm{~b}$ & $0,54 \mathrm{c}$ & $0,80 \mathrm{a}$ & $0,77 \mathrm{ab}$ & $11,637 *$ \\
Taxa de crescimento especifico & 2,37 & 2,31 & 2,28 & 2,30 & $3,794 \mathrm{~ns}$ \\
\hline
\end{tabular}

* Médias na mesma linha seguidas de letras distintas diferem a $(\mathrm{P}<0,05)$ pelo teste Duncan. 
penho produtivo nem a retenção de minerais dessa espécie.

Por outro lado, Furuya et al. (2001) avaliaram dietas com $0,500,1.500$ e 3.000 UF em dietas de origem vegetal suplementadas com $4 \%$ de farinha de peixe e $1,8 \%$ de calcário calcítico e observaram que o ganho de peso apresentou ligeiro aumento até atingirem o nível de 890 UF de inclusão, enquanto os de conversão alimentar aumentou linearmente conforme a inclusão de fitase na dieta. Os autores concluíram que o nível de 700 UF é adequado para o desempenho produtivo dos animais.

Nunes et al. (2006) estudaram a inclusão de amilase, lipase e protease isoladamente nos níveis: 0; 0,05; 0,10 e 0,20 em dietas para juvenis de tambaqui Colossoma macropomum e observaram que as médias mais expressivas dos valores de peso final, ganho de peso, conversão alimentar e taxa de crescimento específico foram obtidos com a inclusão de 0,05 e $0,20 \%$ de amilase e lipase, respectivamente, mas a protease não influenciou os resultados.

A utilização de enzimas exógenas tem sido relacionada à digestibilidade dos nutrientes nos peixes. Gonçalves et al. (2004) avaliaram a digestitiblidade de alimentos de origem vegetal (proteicos e energéticos) suplementados com 0; 1.000 e 2.000 UF e sugeriram que a fitase age de forma diferenciada, pois a inclusão de 2.000 UF não foi suficiente para afetar a digestiblidade da matéria seca, proteína e energia do milho extrusado, do farelo de trigo, do sorgo de baixo tanino, da soja extrusada e do farelo de algodão. Por outro lado, a digestibilidade da matéria seca e energia do milho aumentaram com 1.000 UF e a do farelo de soja e farelo de girassol com 2.000 UF. Essas variações indicam a função do valor biológico, da quantidade de ácido fítico e da natureza dos alimentos.

Oliveira et al. (2007) concluíram que a inclusão de um complexo enzimático composto por celulase, protease e amilase nos níveis de 0; 0,025; 0,050, 0,075 e 0,1\% em dietas formuladas com ingredientes de origem vegetal para tilápias teve efeito quadrático no coeficiente de digestibilidade aparente da matéria seca, proteína bruta e energia bruta, correspondente a 0,049; 0,052 e $0,049 \%$ de inclusão, respectivamente, e que o coeficiente de digestibilidade aparente do amido, cálcio e fósforo aumentou com a inclusão de $0,05 \%$.

Gonçalves et al. (2007) avaliaram a disponibilidade do fósforo com a inclusão de fitase na dieta (0, 1.000 e 2.000 UF) e relataram que a disponibilidade do fósforo varia de acordo com o alimento vegetal. Em alimentos como soja extrusada, farelo de girassol, milho, milho extrusado, sorgo baixo tanino, farelo de arroz, farelo de soja e glúten de milho, a disponibilidade desse mineral pode ser melhorada com a utilização de fitase, entretanto, a suplementação dessa enzima não tem efeito sobre o farelo de trigo e o farelo de algodão. Estes resultados possibilitam a formulação de dietas com esses ingredientes assegurando redução na excreção do fósforo ao meio ambiente.

Ogunkoya et al. (2005) observaram influência de um complexo enzimático composto por amilase, xilanase, protease, celulase e $\alpha$-galactosidase em dietas para truta Oncorhynchus mykiss, que aumentaram os coeficientes de digestibilidade aparente da matéria seca, proteína bruta, lipídios, fósforo e energia. Stone et al. (2003), no entanto, não observaram esse mesmo efeito quando suplementaram dietas com $\alpha$-galactosidas e xilanase para o silver perch (Bidyanus bidyanus).

Não houve diferença $(\mathrm{P}>0,05)$ nos valores médios de matéria seca, umidade, proteína bruta, matéria mineral, retenção de cálcio e fósforo entre os níveis de Cenzyme avaliados (Tabela 4). Por outro lado, o extrato etéreo apresentou redução linear com a elevação dos valores de inclusão do complexo enzimático.

Esses resultados se assemelham aos relatos de Silva et al. (2007b) de que a fitase líquida (0, 250, 500 e $1.000 \mathrm{UF} / \mathrm{kg}$ ) tem efeito negativo nos parâmetros de umidade, proteína bruta, matéria mineral e cálcio nos ossos. No entanto, esses autores observaram efeito quadrático e linear na deposição de fósforo nos ossos dos alevinos de tilápia-do-nilo. Por outro lado, Furuya et al. (2004b) observaram efeito linear na deposição de cálcio e quadrático

Tabela 4 - Composição bromatológica da carcaça de juvenis de tilápia-do-nilo alimentados com dietas contendo complexo enzimático

\begin{tabular}{|c|c|c|c|c|c|}
\hline \multirow[t]{2}{*}{ Item } & \multicolumn{4}{|c|}{ Complexo enzimático (\%) } & \multirow[t]{2}{*}{ CV (\%) } \\
\hline & 0,000 & 0,033 & 0,066 & 0,099 & \\
\hline Umidade & 73,60 & 74,30 & 76,52 & 74,08 & $1,558 \mathrm{~ns}$ \\
\hline Proteína bruta & 14,91 & 14,62 & 15,13 & 14,91 & 5,646ns \\
\hline Matéria mineral & 4,47 & 4,87 & 4,52 & 4,17 & 6,797ns \\
\hline Extrato etéreo ${ }^{1}$ & 6,15 & 5,73 & 5,62 & 5,21 & $22,049 *$ \\
\hline Fósforo na carcaça & 2,25 & 2,22 & 2,24 & 2,16 & $9,175 \mathrm{~ns}$ \\
\hline Cálcio na carcaça & 32,69 & 26,71 & 26,58 & 26,24 & $32,922 \mathrm{~ns}$ \\
\hline
\end{tabular}

* $(\mathrm{P}<0,05) ;{ }^{1}$ Efeito linear $\mathrm{Y}=-8,0089 \mathrm{x}+6,117, \mathrm{r}^{2}=0,96$. 
na retenção de fósforo quando avaliaram a inclusão de $0,500,1.000,2.000$ e $4.000 \mathrm{UF} / \mathrm{kg}$ em dietas para alevinos de tilápia, comprovando que a suplementação com 2.000 UF favorece a retenção de fósforo na carcaça dos alevinos de tilápia.

Neste trabalho, a suplementação da dieta com complexo enzimático Cenzyme ${ }^{\circledR}$ melhorou a conversão e eficiência alimentar, mas não influenciou o peso final e a composição química da carcaça dos animais. Contudo, o teor de extrato etéreo apresentou redução linear com a inclusão dessas enzimas.

\section{Conclusões}

A utilização de 0,066\% de complexo enzimático Cenzyme ${ }^{\circledR}$ (amilase, protease, celulase, lipase, pectinase, xilanase, -glucanase e fitase) em dietas para juvenis de tilápia-do-nilo não interfere no desempenho dos peixes, mas melhora a conversão e a eficiência alimentar.

\section{Referências}

ASSOCIATION OF OFFICIAL ANALYTICAL CHEMISTS - AOAC. Oficial Methods of analysis of Association of Official Analytical Chemists. 17.ed. Arlington: AOAC, 2000. v.1/2.

BEDFORD, M.R. Exogenus enzymes in monogastric nutrition their current value and future benefits. Animal Feed Science and Technology, v.86, p.1-13, 2000.

BOCK, C.L; PEZZATO, L.E.; CANTELMO, O.A. et al. Fitase e digestibilidade aparente de nutrientes de rações por tilápias do Nilo. Revista Brasileira de Zootecnia, v.35, n.6, p.2198-2202, 2006.

BOCK, C.L.; PEZZATO, L.E.; CANTELMO, O.A. et al. Fitase em rações para tilápia do Nilo na fase de crescimento. Revista Brasileira de Zootecnia, v.36, n.5, p.1455-1461, 2007.

BOSCOLO, W.R.; HAYASHI, C,; MEURER, F. Digestibilidade aparente da energia e nutrientes de alimentos convencionais e alternativos para a tilápia do Nilo (Oreochromis niloticus, L.). Revista Brasileira de Zootecnia, v.13, n.2, p.539-545, 2002.

BOSCOLO, W.R.; HAYASHI, C.; FEIDEN, A. et al. Composição química e digestibilidade aparente da energia e nutrientes da farinha de resíduos da indústria de filetagem de tilápias, para a tilápia do Nilo (Oreochromis niloticus). Ciência Rural, v.38, n.9, p.2579-2586, 2008.

BOYD, C. Water quality in ponds for aquaculture. Alabama: Birmingham, 1990. 482p.

CHAMP, P.C.P.; HARVEY, R.A.; FERRIER, D.R. Bioquímica ilustrada. Porto Alegre: Artmed, 2006. 544p.

CORREA, C.F.; AGUIAR, L.H.; LUNDSTEDT, L.M. et al. Responses of digestive enzymes of tambaqui (Colossoma macropomum) to dietary constarch changes and metabolic inferences. Comparative Biochemistry and Physiology, v.147, p.857-862, 2007.

COSTA, F.G.P.; CLEMENTINO, R.H.; JÁCOME, I.M.T.D. et al. Utilização de um complexo multienzimático em dietas de frangos de corte. Ciência Animal Brasileira, v.5, n.2, p.63-71, 2004.

COTTA, T.; TORRES, D.M.; OLIVEIRA, A.I.G. Efeitos da adição de um complexo enzimático sobre o desempenho de frangos de corte. Ciência Agrotecnológica, v.26, n.4, p.852-857, 2002.
FISCHER, G.; MAIER, J.C.; RUTZ, F. et al. Desempenho de frangos de corte alimentados com dietas a base de milho e farelo de soja, com ou sem adição de enzimas. Revista Brasileira de Zootecnia, v.31, n.1, p.402-410, 2002.

FRANCIS, G.; MAKKAR, H.P.S. BECKER, K. Antinutritional factores present in plant-derived alternate fish feedingredients and their effects in fish. Aquaculture, v.199, p.197-227, 2001.

FUKAYAMA, E.H.; SAKAMURA, N.K.; DOURADO, L.R.B. et al. Efeito da suplementação de fitase sobre o desempenho e a digestibilidade dos nutrientes em frangos de corte. Revista Brasileira de Zootecnia, v.37, n.4, p.629-635, 2008.

FURUYA, W.M.; BOTARO, D.; SILVA, L.C.R. et al. Fitase em dietas para a tilápia do Nilo (Oreochromis niloticus) (175 a 327 g). Archivos de Zootecnia, v.55, n.210, p.161-170, 2006.

FURUYA, W.M.; GONÇALVES, G.S. FURUYA, V.R.B. et al. Fitase na alimentação de tilápia do Nilo (Oreochromis niloticus). Desempenho e digestibilidade. Revista Brasileira de Zootecnia, v.30, n.3, p. 924-929, 2001.

FURUYA, W.M.; PEZZATO, L.E.; BARROS, M.M. et al. Use of ideal protein concept for precision formulation of amino acid levels in fish-meal-free diets for juvenile Nile tilapia (Oreochromis niloticus L.). Aquaculture Reserch, v.35, p.1110-1116, 2004a.

FURUYA, W.M.; NEVES, P.R.; SILVA, L.C.R. et al. Fitase na alimentação da tilápia do Nilo (Oreochromis niloticus) durante o período de reversão de sexo. Acta Scientiarum, v.26, n.3, p.299-303, 2004b.

GARCIA, E.R.M.; MURAKAMI, A.E.; BRANCO, A.F. et al. Efeito da suplementação enzimática em rações com farelo de soja e soja integral extrusada sobre a digestibilidade de nutrientes, o fluxo de nutrientes na digesta ileal e o desempenho de frangos. Revista Brasileira de Zootecnia, v.29, n.5, p.1414-1426, 2000.

GOMES, P.C.; RAMALHO, R.M.; ROSTAGNO, H.S. et al. Efeito do complexo multienzimático nos valores de energia metabolizavel e coeficientes de digestibilidade dos aminoácidos do triticale para aves. Revista Brasileira de Zootecnia, v.29, n.6, p.2268-2275, 2000.

GONÇALVES, G.S.; PEZZATO, L.E.; BARROS, M.M. et al. Digestibilidade aparente e suplementação de fitase em alimentos vegetais para a tilapia do Nilo. Acta Scientiarum, v.26, n.3, p.313-321, 2004.

GONÇALVES, G.S.; PEZZATO, L.E.; PADilha, P.M. et al. Disponibilidade aparente do fósforo em alimentos vegetais e suplementação da enzima fitase para tilapia do Nilo. Revista Brasileira de Zootecnia, v.36, n.5, p.1473-1480, 2007.

MARENGONI, N.G. Produção de tilápia do Nilo Oreochromis niloticus (linhagem chitraladra), cultivada em tanques-rede, sob diferentes densidades de estocagem. Archivos de Zootecnia, v.55, n.210, p.127-138, 2006.

MEURER, F.; HAYASHI, C.; BOSCOLO, W.R. Digestibilidade aparente de alguns alimentos protéicos pela tilápia do Nilo (Oreochromis niloticus). Revista Brasileira de Zootecnia, v.32, n.6, p.1801-1809, 2003.

MOURA, G.S.; ALIVEIRA, M.G.A.; LANNA, E.T.A. et al. Desempenho e atividade de amilase em tilápias do Nilo submetidas a diferentes temperaturas. Pesquisa Agropecuária Brasileira, v.42, n.11, p.1609-1615, 2007.

NATIONAL RESEARCH COUNCIL - NRC. Nutrient requirements of fishes. Washington, D.C.: Academic Press, 1993,114p.

NERY, V.L.H.; LIMA, J.A.; NELO, R.C.A. Adição de enzimas exógenas para leitões de 10 aos $30 \mathrm{~kg}$ de peso. Revista Brasileira de Zootecnia, v.29, n.3, p.794-802, 2000.

NG, W.K.; LIM, H.A.; LIN, S.L. et al. Nutritive value of palm kernel meal pretreated with enzyme or fermented with trichoderma koningii (Oudemans) as a dietary ingredient for red hydrid tilapia (Oreochromis sp.). Aquaculture Reaserch, v.33, p.1199-1207, 2002.

NUNES, E.S.S.; CAVERO, B.A.S.; PEREIRA-FILHO, M. et al. Enzimas digestivas exógenas na alimentação de juvenis de 
tambaqui. Pesquisa Agropecuária Brasileira, v.41, n.1, p.139-143, 2006.

OGUNKOYA, A.E.; PAGE, G.L; ADEWOLU, M.A. et al. Dietary incorporation of soybean meal and exogenous enzyme cocktail can affect physical characteristics of faecal material egested by rainbow trout (Oncorhyncus mykiss). Aquaculture, v.254, p.466-475, 2005.

OLIVEIRA, G.R.; LOGATO, P.V.R.; FREITAS, R.T.F. et al. Digestibilidade de nutrientes em rações com complexo multienximatico para a tilápia do Nilo. Revista Brasileira de Zootecnia, v.36, n.6, p.1945-1952, 2007.

OLIVIA-TELES, A.; PEREIRA, J.P.; GOUVEIA, A. et al. Utilization of diets supplemented with microbial phytase by seabass. Aquatic Living Resources, v.11, n.4, p.225-259, 1998.

ROCHA, C.B.; POUEY, J.L.O.F.; LOPES, P.R.S. et al. Suplementação da enzima fitase e o desempenho e retenção mineral em juvenis de jundia (Rhamdia quelen). Boletim do Instituto de Pesca, v.34, n.1, p.153-159, 2008.

RUIZ, U.S.; THOMAZ, M.C.; HANNAS, M.I. et al. Complexo enzimático para suínos: digestão, metabolismo, desempenho e impacto ambiental. Revista Brasileira de Zootecnia, v.37, n.3, p.458-468, 2008.

SAJJADI, M.; CARTER, C.G. Dietary phytase supplementation and utilization of phosforus by Atlantic salmom (Salmo salar) fed a canola meal dasead diet. Aquaculture, v.240, p.417-431, 2004.

SAMPAIO, J.M.C.; BRAGA, L.G.T. Cultivo de tilápia em tanquesrede de na barragem do Ribeirão de Saloméa - Floresta Azul Bahia. Revista Brasileira de Saúde e Produção Animal, v.6, n.2, p.42-52, 2005.

SILVA, H.O.; FONSECA, R.A.; FILHO, R.S.G. et al. Características produtivas e digestibilidade da farinha de folhas de mandioca em dietas de frangos de corte com e sem adição de enzimas. Revista Brasileira de Zootecnia, v.29, n.3, p.823-829, 2000.

SILVA, J.A.M.; FIALHO, M.P; CAVERO, B.A.S. et al. Digestibilidade aparente de nutrientes e energia de ração suplementada com enzimas exógenas para juvenis de tambaqui (Colossoma macropomum Cuvier, 1818). Acta Amazônica, v.37, n.1, p.157-164, 2007a.

SILVA, T.S.C.; FURUYA, W.M.; SANTOS, L.D. et al. Fitase líquida em dieta extrusada para juvenis de tilápia do Nilo (Oreochromis niloticus). Acta Scientiarum, v.29, n.4, p.449-455, 2007b.

SILVA, Y.L.; RODRIGUES, P.B.; FREITAS, R.T.F. et al. Níveis de proteína e fósforo em rações para frangos de corte, na fase de 14 a 21 dias de idade. Valores energéticos e digestibilidade de nutrientes. Revista Brasileira de Zootecnia, v.37, n.3, p.469-477, 2008.

SIPAÚBA-TAVARES, L.H.S. Limnologia aplicada à aqüicultura. Jaboticabal: Funep, 1995. 72p.

STONE, D.A.J.; ALLAN,G.L.; ANDERSON, A.J. et al. Carbohydrate utilization by juvenile silver perca Bidyanus bidyanus (Mitchell). II Digetibility and utilization of starch and its breakdown products. Aquaculture Research, v.34, n.2, p.109-121, 2003.

TEIXEIRA, A.O.; LOPES, D.C.; FERREIRA, V.P.A. et al. Utilização de enzimas exógenas em dietas com diferentes fontes e níveis de proteína para leitões na fase de creche. Revista Brasileira de Zootecnia, v.34, n.3, p.900-906, 2005.

TEJEDOR, A.A.; ALBINO, L.F.T.; ROSTAGNO, H.S. et al. Efeito da adição de enzimas em dietas de frangos de corte à base de milho e farelo de soja sobre a digestibilidade ileal de nutrientes. Revista Brasileira de Zootecnia, v.30, n.3, p.809-816, 2001.

TORRES, D.M.; COTTA, J.T.B.; TEIXEIRA, A.S. et al. Dietas a base de milho e farelo de soja suplementadas com enzimas na alimentação de frangos de corte. Ciência Agrotecnológica, v.27, n.1, p.199-205, 2003.

UNIVERSIDADE FEDERAL DE VIÇOSA. UFV. 1997. SAEG Sistema para análises estatísticas e genéticas. Versão 7.1. Viçosa, MG. 150p. (Manual do usuário).

VIELMA, J.; MAKINEN, T.; EKHOLM, P. et al. Influence of dietary soy and phytase levels on performance and body composition of larg rainbow trout (Oncorhynchus mykiss) and algal avaibility of phosphorus load. Aquaculture, v.182, p.349-362, 1998. 